\title{
Vascular Function and Myocardial Performance Indices in Children Born Small for Gestational Age
}

\author{
Maria Felicia Faienza, MD; Giacomina Brunetti, PhD; Maurizio Delvecchio, MD, PhD; \\ Annapaola Zito, MD; Fabrizia De Palma, MD; Francesca Cortese, MD; Adriana Nitti, MD; \\ Elena Massari, MD; Michele Gesualdo, MD; Gabriella Ricci, MD; Santa Carbonara, MD; \\ Paola Giordano, MD; Luciano Cavallo, MD; Pietro Scicchitano, MD; Marco Matteo Ciccone, MD
}

\begin{abstract}
Background: Small-for-gestational-age (SGA) children have increased cardiovascular risk, but the mediating factors are poorly understood. We hypothesized that birth size could affect the cardiovascular system since childhood in the absence of other risk factors. We investigated endothelial and myocardial function in SGA children with regular catch-up growth.
\end{abstract}

Methods and Results: Biochemical markers, blood pressure, flow-mediated vasodilation (FMD), common carotid intima-media thickness (cIMT), anteroposterior diameter of the infrarenal abdominal aorta (APAO) and echocardiographic parameters of left and right ventricular (LV and RV) function were studied in 27 SGA and 25 appropriate-forgestational-age (AGA) subjects. SGA subjects had a higher homeostasis model assessment index than controls (2.61 \pm 1.27 vs. $1.56 \pm 0.40, P=0.01)$, higher $\operatorname{clMT}(0.51 \pm 0.04 \mathrm{~mm}$ vs. $0.45 \pm 0.07 \mathrm{~mm}, \mathrm{P}=0.007)$ and $A P A O(1.31 \pm 1.35 \mathrm{~cm}$ vs. $1.30 \pm 0.16 \mathrm{~cm}, P=0.005)$, and lower FMD (10.11 $\pm 4.17 \%$ vs. $12.34 \pm 4.28, P=0.04)$ than controls. On echocardiography SGA had higher Tei index both at $L V$ and $R V$ than controls $(P=0.001)$. Reduced $R V$ systolic function was also observed in SGA subjects.

Conclusions: SGA subjects had vascular morphological and function abnormalities compared with AGA, which increase their cardiovascular risk profile. Furthermore, a subtle cardiac alteration in both RV and LV functions was seen in SGA patients compared with AGA. (Circ $J$ 2016; 80: 958-963)

Key Words: Anteroposterior diameter; Carotid intima-media thickness; Flow-mediated vasodilation; Infrarenal abdominal aorta; Small for gestational age

$\mathbf{S}$ mall for gestational age (SGA) is a condition that affects approximately $3-10 \%$ of newborns whose birth weight and/or length are at least $2 \mathrm{SD}$ below the mean for gestational age. ${ }^{1}$ Most SGA children have catch-up growth during the first $2-4$ years of life, but approximately $15 \%$ of them continue to be short throughout childhood, adolescence and adulthood. ${ }^{2}$ Children born SGA have an increased risk of developing permanent metabolic changes as a consequence of intrauterine reprogramming, which lead to increased cardiovascular (CV) risk, excess abdominal fat and type 2 diabetes in adulthood. ${ }^{3,4}$ Additionally, low birth weight combined with rapid postnatal growth appears to be associated with impaired glucose tolerance, ${ }^{5}$ obesity $^{5}$ and non-alcoholic fatty liver disease, ${ }^{6,7}$ whereas rapid growth after 2 years of age may increase the risk for CV disease (CVD). ${ }^{8}$ In particular, childhood weight gain rather than birth size seems to affect both blood pressure and common carotid intima-media thickness (cIMT) in young adults. ${ }^{9-11}$

\section{Editorial p 818}

Increased vascular IMT has been demonstrated in SGA aged 3-6 years, ${ }^{12}$ irrespective of the presence or absence of prenatal risk factors for intrauterine growth restriction. ${ }^{13}$

Furthermore, early endothelial dysfunction has been demonstrated in young adults born with low birth weight, particularly in those who did not have other CV risk factors. ${ }^{14}$

These findings support the hypothesis that the CV alterations in children born SGA are due to fetal CV reprogramming rather than to prenatal and postnatal risk factors. Therefore,

Received September 29, 2015; revised manuscript received January 10, 2016; accepted January 12, 2016; released online February 10, 2016 Time for primary review: 21 days

Department of Biomedical Sciences and Human Oncology, Section of Pediatrics (M.F.F., M.D., F.D.P., A.N., P.G., L.C.), Department of Basic and Medical Sciences, Neurosciences and Sense Organs, Section of Human Anatomy and Histology (G.B.), Cardiovascular Diseases Section, Department of Emergency and Organ Transplantation (A.Z., F.C., M.G., G.R., S.C., M.M.C.), University “A. Moro”, Bari; Department of Pediatric Cardiology, Giovanni XXIII Pediatric Hospital, Bari (E.M.); and Cardiology Unit, Hospital "F. Perinei", Bari (P.S.), Italy

Mailing address: Maria Felicia Faienza, MD, Department of Biomedical Science and Human Oncology, Section of Pediatrics, University

"Aldo Moro" Bari, Piazza G. Cesare, 11, 70124 Bari, Italy. E-mail mariafelicia.faienza@uniba.it

ISSN-1346-9843 doi:10.1253/circj.CJ-15-1038

All rights are reserved to the Japanese Circulation Society. For permissions, please e-mail: cj@j-circ.or.jp 
subjects born SGA could develop early impairment in vascular morphology and function. One more interesting question is whether SGA children are at increased risk for myocardial function alterations, a subtle cardiomyopathy whose future evolution is still unknown. The literature contains contrasting results: some authors reported altered cardiac performance in SGA individuals as compared with subjects born appropriate for gestational age (AGA), ${ }^{15-17}$ while others found no influence of low birth length and/or weight on future development of early cardiac dysfunction. ${ }^{18,19}$

We hypothesized that birth size could affect the CV system since childhood in the absence of other risk factors. We therefore investigated endothelial and myocardial function by evaluating cIMT, flow-mediated dilatation (FMD) of brachial artery, anteroposterior diameter of infra-renal abdominal aorta (APAO) and echocardiographic tissue Doppler imaging (TDI) markers in a group of children born SGA with regular catchup growth within the first year of life.

\section{Methods}

\section{Patients}

Twenty-seven children (15 male; mean age, $10.03 \pm 3.0$ years) out of 30 meeting the inclusion criteria agreed to participate to this study. All children were born at term at the Neonatology Unit at University "Aldo Moro" Bari, Italy, and were classified as SGA (birth weight and/or length $<3$ rd percentile for gestational age). ${ }^{20}$ In particular, 11 subjects were SGA for weight, 13 for weight and length and the remaining 3 only for length. They were followed up for the first 4 years of life at the Pediatric Endocrinology Unit according to established followup in SGA subjects. Between January and September 2014, they were invited by telephone to participate in the study. All subjects had weight gain equally distributed in the first 6 months of life and continued to have regular growth during the first year of life. Catch-up growth was defined as attainment of height centile within the midparental height range. ${ }^{21}$

Medical and family history was obtained from all subjects. Exclusion criteria were renal, liver and/or CVD, hypertension, metabolic and/or endocrine disorders, genetic syndromes, history of chronic allergy, and acute infectious or inflammatory disease during the 3 months preceding the study. Physical examination, including anthropometric parameters (height, weight, body mass index-standard deviation score; BMI-SDS) using Italian growth charts, ${ }^{22}$ and assessment of pubertal stage according to Tanner criteria were performed. ${ }^{23}$ Both systolic blood pressure (SBP) and diastolic blood pressure (DBP) were measured in all patients from the right brachial artery using a mercury gauge in the supine position prior to examination after resting for a minimum of $5 \mathrm{~min}$.

The control group consisted of 25 healthy children born at term and AGA (birth weight $>-2$ SDS and $<+2$ SDS), matched for age, gender and BMI-SDS. The control group was recruited on a voluntary basis in the outpatient clinic and consisted of children referred to hospital for minor surgery or electrocardiography for minor trauma to head, limbs, or chest pain All subjects were in good general health and were not taking drugs in the last 3 months.

Written informed consent was obtained from the children's parents. All procedures were in accordance with the guidelines of the Helsinki Declaration on Human Experimentation and were approved by the local ethics committee.

\section{Biochemistry}

Blood glucose, insulin, total cholesterol (TC), high-density lipoprotein cholesterol (HDL-C) and low-density lipoprotein cholesterol (LDL-C), and triglycerides (TG) were measured after overnight fasting in all subjects.

TC, LDL-C, HDL-C and TG within the 5th and the 95th percentiles were defined as normal. ${ }^{24}$ Insulin resistance (IR) was measured using the homeostasis model assessment (HOMA) index, calculated as insulin $(\mu \mathrm{U} / \mathrm{ml}) \times$ blood glucose $(\mathrm{mmol} / \mathrm{L}) / 22.5 .^{25} \mathrm{IR}$ was defined as HOMA-IR $>2.5 .{ }^{25}$

\section{Ultrasonography}

SGA children and controls underwent high-definition vascular and cardiac ultrasound assessment according to the following protocols in order to identify arteries with early atherosclerotic lesions and/or early signs of cardiac function impairment.

cIMT Ultrasonographic echo-color Doppler study of left and right common carotid arteries was performed bilaterally by the same physician with a Philips Sonos 5500 using a 7.5$\mathrm{MHz}$ high-resolution probe. The patients were placed in the supine position, with the neck extended and rotated contralaterally by $45^{\circ}$, and the common carotid arteries were examined on the sagittal axis in lateral view. cIMT was defined as a low-level echo gray band not projecting into the arterial lumen, and was measured during end-diastole according to the method described by Pignoli et al. ${ }^{26}$ The measurements were performed bilaterally $1 \mathrm{~cm}$ proximally to the carotid bulb, 3 times, and then mean cIMT was calculated. ${ }^{27,28}$ Intra-observer variability was good (intraclass correlation coefficient $[\mathrm{ICC}]=0.99$; good if $>0.80){ }^{29}$

FMD of the Brachial Artery All the patients were fasted (including avoidance of stimulants such as coffee/tea, chocolate) and physical exercise free for at least $8-12 \mathrm{~h}$ before the examination in order to avoid negative influences on test results. The tests were carried out in a quiet air conditioned room $\left(22-24^{\circ} \mathrm{C}\right)$, early in the morning. We performed a preliminary scan in order to explore the anatomy and identify landmarks. The scan was done at the right brachial artery on long-axis projection between 5 and $10 \mathrm{~cm}$ above the elbow using a $\geq 7.0$ $\mathrm{MHz}$ linear probe. The study was performed using a highresolution ultrasonograph (Philips Sonos 5500) connected to an image analysis system, certified by the National Research Council of Pisa (MVE II), for computing the brachial artery diameter in real-time by analyzing B-mode ultrasound images. ${ }^{30}$ All the ultrasound examinations were performed by the same physician in order to reduce observer bias. With the subject in a supine position for at least $10 \mathrm{~min}$, the arm was positioned comfortably in order to identify the humeral artery. A sphygmomanometer cuff was placed distally to the artery. After $1 \mathrm{~min}$ of flow image baseline acquisition, the artery was occluded by inflating the cuff to a pressure of $200-220 \mathrm{mmHg}$ for exactly $5 \mathrm{~min}$. After deflation, the following increased shear stress provides the stimulus for the dilatation of the humeral artery. Within $15 \mathrm{~s}$ from the end of ischemia, the flow rate was measured and then the degree of hyperemia. The image of the artery was then recorded continuously for 2-3 min after ischemia. Reactive hyperemia was calculated as the ratio of the change in diameter (maximum dilatation after deflation-baseline) divided by the baseline, which corresponds to maximum FMD recovery. FMD was analyzed as the percentage increase in brachial artery diameter after the application of a pressure stimulus. ${ }^{28,31}$ Intra-observer variability was good (ICC=0.93).

APAO To improve the image acquisition, subjects were asked to keep fasting for at least $8-12 \mathrm{~h}$ and to follow a fiber diet for the 2 days prior to the examination to reduce intestinal bloating (diet preparation). Ultrasonography of the infra-renal abdominal aorta was performed by a single operator using a 


\begin{tabular}{|c|c|c|c|}
\hline & SGA & Controls & $\mathrm{P}$-value \\
\hline Subjects (n) & 27 & 25 & - \\
\hline Age (years) & $10.03 \pm 3.0$ & $10.41 \pm 3.9$ & 0.17 \\
\hline Gender (M/F) & $15 / 12$ & $13 / 12$ & 0.25 \\
\hline Tanner (I/II) & $15 / 12$ & $12 / 13$ & 0.33 \\
\hline Birth weight (kg) & $2.268 \pm 0.4$ & $3.25 \pm 0.37$ & 0.0001 \\
\hline Birth length (cm) & $45.9 \pm 3.6$ & $49.71 \pm 3.81$ & 0.01 \\
\hline Weight-SDS & $0.23 \pm 1.05$ & $0.22 \pm 0.67$ & 0.40 \\
\hline Height-SDS & $0.34 \pm 0.91$ & $0.31 \pm 0.74$ & 0.21 \\
\hline BMI-SDS & $0.09 \pm 1.23$ & $0.1 \pm 0.64$ & 0.32 \\
\hline $\mathrm{SBP}(\mathrm{mmHg})$ & $103.65 \pm 2.28$ & $107 \pm 2.54$ & 0.51 \\
\hline $\mathrm{DBP}(\mathrm{mmHg})$ & $63.26 \pm 6.29$ & $64.04 \pm 3.39$ & 0.33 \\
\hline Glucose (mg/dl) & $85 \pm 12$ & $81.16 \pm 8.14$ & 0.20 \\
\hline Insulin $(\mu \mathrm{U} / \mathrm{ml})$ & $12.15 \pm 5.25$ & $9.74 \pm 4.59$ & 0.27 \\
\hline HOMA-IR & $2.61 \pm 1.27(1.01-5.27)$ & $1.56 \pm 0.40(0.96-2.00)$ & 0.01 \\
\hline Triglycerides (mg/dl) & $73 \pm 44$ & $57.24 \pm 19.16$ & 0.46 \\
\hline $\mathrm{TC}(\mathrm{mg} / \mathrm{dl})$ & $165 \pm 31$ & $144.8 \pm 28.32$ & 0.20 \\
\hline HDL-C (mg/dl) & $55 \pm 9$ & $58.67 \pm 9.30$ & 0.252 \\
\hline LDL-C (mg/dl) & $83.4 \pm 23.5$ & $78.10 \pm 21.03$ & 0.39 \\
\hline
\end{tabular}

Data given as mean \pm SD (range). BMI, body mass index; DBP, diastolic blood pressure; HDL-C, high-density lipoprotein cholesterol; HOMA, homeostasis model assessment; IR, insulin resistance; LDL-C, low-density lipoprotein cholesterol; SBP, systolic blood pressure; SDS, standard deviation score; SGA, small for gestational age; TC, total cholesterol.

single high-resolution vascular ultrasound Philips 5500 equipped with a $3-\mathrm{MHz}$ electronic probe. With the patient in a supine position, the electronic probe was placed $1 \mathrm{~cm}$ left of the umbilicus. The best image in long-axis projection of the abdominal aorta was then obtained. APAO was defined as the maximum external cross-sectional measurement. ${ }^{30}$ It was calculated as the distance between the near and the far walls of the abdominal aorta. Measurements were performed $2 \mathrm{~cm}$ above and distal to the umbilicus and expressed in centimeters. ${ }^{30}$ Intraobserver variability was good $(\mathrm{ICC}=0.97)$.

\section{M-Mode, B-Mode Echocardiography and TDI}

All patients underwent echocardiography of both the left and right chambers, in agreement with international guidelines. ${ }^{32}$ Pulsed-wave TDI was used in order to evaluate the velocity of the ventricle walls and the related parameters of systolic and diastolic function of both the left and right ventricles (LV and RV). ${ }^{33}$ TDI information is less load dependent than standard Doppler. ${ }^{34}$ On apical 4-chamber projection, the cardiac structures examined were the mitral valve annulus, both lateral and medial, the basal and mid part of the LV lateral wall and interventricular septum, the basal part of the RV lateral wall and the lateral tricuspid annulus. ${ }^{35}$ We considered as main parameters: systolic velocity (S'); early diastolic velocity (E'); and late diastolic velocity $\left(\mathrm{A}^{\prime}\right)$. We calculated E'/Avfor all the anatomic territories considered and $\mathrm{E} / \mathrm{E}^{\prime}$ at the lateral and medial parts of the mitral annulus. Systolic and diastolic time parameters related to both the RV and LV were measured throughout the entire cardiac cycle: ${ }^{33-36}$ for the LV, isovolumetric contraction time (l-IVCT), ejection time (l-ET), isovolumetric relaxation time (l-IVRT) were used to obtain the LV Tei index [(1-IVRT+1-IVCT)/l-ET]; and for the RV, isovolumetric contraction time (r-IVCT), ejection time (r-ET), and isovolumetric relaxation time (r-IVRT) were used to obtain the RV Tei index [(r-IVRT+r-IVCT)/r-ET].

In order to evaluate the reproducibility of the echocardiographic evaluations, we calculated the intra-observer variabil- ity: $\mathrm{ICC}=0.87$.

\section{Statistical Analysis}

For statistical analysis, SPSS for Windows, version 22.0 (SPSS, Chicago, IL, USA) were used. Results are given as mean \pm SD. The Kolmogorov-Smirnov test was applied to test normality of distribution. In parameters with normal distribution, means were compared using unpaired Student t-test, whereas linear correlations were calculated using Pearson's correlation coefficient; in parameters with skewed distribution, significance was assessed with the Mann-Whitney test and Spearman's correlation coefficient, respectively. Finally, multiple regression analysis was used to determine the relative strength of each biochemical and clinical variable in predicting CV parameters. The limit of statistical significance was set at 0.05 .

\section{Results}

Baseline clinical characteristics, biochemical markers of glucidic and lipid metabolism, and HOMA-IR index are listed in Table 1. No significant differences were found between SGA children and controls according to age, sex, pubertal stage, weight, height, BMI-SDS, SPB and DBP. Blood glucose level was normal in all examined subjects, but HOMA-IR was significantly higher in SGA children compared with controls (2.61 \pm 1.27 vs. $1.56 \pm 0.40, \mathrm{P}=0.01)$. No statistically significant differences for TC, HDL-C and LDL-C, and TG were seen between SGA children and controls. We did not observe any differences between SGA groups according to metabolic and cardiovascular risk parameters.

\section{Vascular Assessment}

c-IMT, FMD and APAO are listed in Table 2. Mean cIMT was significantly higher in SGA children than controls (0.51土 $0.04 \mathrm{~mm}$ vs. $0.45 \pm 0.07 \mathrm{~mm}, \mathrm{P}=0.007)$. Furthermore, SGA subjects had statistically significantly worsened endothelial function as compared with healthy controls $(10.11 \pm 4.17 \%$ vs. 


\begin{tabular}{lccc}
\hline \multicolumn{2}{c|}{ Table 2. Vascular and Echocardiographic } & Parameters & \\
\multicolumn{1}{c}{ Ultrasound parameters } & SGA & Controls & P-value \\
Mean cIMT $(\mathrm{mm})$ & $0.51 \pm 0.04$ & $0.45 \pm 0.07$ & 0.007 \\
FMD $(\%)$ & $10.11 \pm 4.17$ & $12.34 \pm 4.28$ & 0.04 \\
APAO $(\mathrm{cm})$ & $1.31 \pm 1.35$ & $1.30 \pm 0.16$ & 0.005 \\
TAPSE $(\mathrm{mm})$ & $21.54 \pm 4.75$ & $27.03 \pm 1.89$ & 0.002 \\
LVEF $(\%)$ & $62.55 \pm 6.29$ & $59.62 \pm 0.10$ & 0.001 \\
LV Tei index & $0.41 \pm 0.07$ & $0.24 \pm 0.20$ & 0.001 \\
RV Tei index & $0.41 \pm 0.09$ & $0.16 \pm 0.10$ & 0.001 \\
Left E/A ratio & $2.14 \pm 0.47$ & $1.50 \pm 0.89$ & 0.001 \\
Right E/A ratio & $1.94 \pm 1.83$ & $1.33 \pm 0.10$ & 0.001 \\
E/e' ratio & $8.10 \pm 1.59$ & $11.91 \pm 0.89$ & 0.001 \\
\hline
\end{tabular}

Data given as mean \pm SD. APAO, anteroposterior diameter of the infrarenal abdominal aorta diameter; clMT, carotid intima-media thickness; FMD, flow-mediated dilatation; LV, left ventricular; LVEF, LV ejection fraction; RV, right ventricular; SGA, small for gestational age; TAPSE, tricuspid annular plane systolic excursion.

$12.34 \pm 4.28 \%, \mathrm{P}=0.04)$. There was also a statistically significant increase in APAO in SGA patients compared with controls $(1.31 \pm 1.35 \mathrm{~cm}$ vs. $1.30 \pm 0.16 \mathrm{~cm}, \mathrm{P}=0.005)$.

Mean cIMT was positively related to age $(r=0.367, \mathrm{P}=0.05)$, while FMD was inversely correlated with age $(\mathrm{r}=-0.660$, $\mathrm{P}=0.0003)$, and TC $(\mathrm{r}=-0.231, \mathrm{P}=0.001)$.

\section{Echocardiography}

Interesting insights came from the echocardiographic evaluation of both RV and LV function. SGA subjects had increased left Tei index $(0.41 \pm 0.07$ vs. $0.24 \pm 0.20, \mathrm{P}=0.001)$ and right Tei index $(0.41 \pm 0.09$ vs. $0.16 \pm 0.10, \mathrm{P}=0.001)$ compared with healthy controls (Table 2). Furthermore, even indirect markers of systolic RV function (ie, tricuspid annular plane systolic excursion [TAPSE]) were reduced in SGA subjects as compared with controls $(21.54 \pm 4.75 \mathrm{~mm}$ vs. $27.03 \pm 1.89 \mathrm{~mm}$, $\mathrm{P}=0.002)$. We also observed an increase in both left $(2.14 \pm 0.47$ vs. $1.50 \pm 0.89, \mathrm{P}=0.001)$ and right $(1.94 \pm 1.83$ vs. $1.33 \pm 0.10$, $\mathrm{P}=0.001$ ) $\mathrm{E} / \mathrm{A}$ for the 2 groups (Table 2). SGA subjects had higher LV ejection fraction (LVEF) as compared with AGA subjects $(62.55 \pm 6.29 \%$ vs. $59.62 \pm 0.10 \% \mathrm{P}=0.001)$. As regards the influence of birth weight, we found a negative correlation with LVEF $(r=-0.320, P<0.0001)$ and RV Tei index $(r=-0.230$, $\mathrm{P}<0.0001)$.

\section{Multiple Regression Analysis}

In SGA subjects, cIMT was significantly influenced by HOMAIR $(\beta=0.159)$ and LDL-C $(\beta=0.294 ; \mathrm{r}=0.359, \mathrm{P}=0.0001)$, while left $\mathrm{E} / \mathrm{A}$ was negatively influenced by HOMA-IR $(\beta=-0.333)$ and positively by HDL-C ( $\beta=0.360 ; \mathrm{r}=0.480, \mathrm{P}=0.0001)$, on multiple regression analysis. Multiple regression analysis also showed that metabolic parameters did not influence APAO and TAPSE.

\section{Discussion}

The present study has shown that SGA subjects have an early, subtle impairment of the CV system, the implications of which for overall growth and outcomes are still unknown.

Vascular and echocardiographic comparisons of SGA and AGA controls identified the following: (1) morphological alterations in the systemic arterial vessels in SGA subjects, as reflected by increased cIMT and APAO; (2) reduced endothelial function in SGA subjects; and (3) right and left cardiac chamber alterations in both systolic and diastolic function in SGA subjects, as reflected by left and right Tei index and/or
TAPSE.

It is well established that the atherosclerotic process starts in childhood and proceeds silently over a long period of time before clinical manifestations. ${ }^{37} \mathrm{SGA}$ is associated with the risk of atherosclerosis, ${ }^{38,39}$ probably due to the increase of risk factors for the development of metabolic syndrome, particularly in SGA subjects with spontaneous catch-up growth. ${ }^{40}$ The present SGA subjects had statistically significantly higher HOMA-IR compared with the AGA subjects, indicating an insulin-resistant condition that is well known to induce acceleration of the systemic atherosclerotic process. ${ }^{30}$ The present SGA subjects had reduced FMD. In our previous study such endothelial dysfunction in SGA patients was found to be related to a dysfunction in endothelial progenitor cells resulting in reduced proliferation and migration of such cells. ${ }^{41}$ Such a condition might be triggered by an anti-angiogenic state enhanced by the low birth weight via alteration of the vascular endothelial growth factor pathway. ${ }^{41}$ Unfortunately, this explanation of endothelial dysfunction in the present subjects is an hypothesis only, because we did not evaluate endothelial progenitor cells.

The role of birth weight on endothelial vasodilatation was also supported by Touwslager et $\mathrm{al},{ }^{42}$ who demonstrated that the vessels' dilatation after acetylcholine use was related to anthropometric parameters of the newborns such as birth weight, length and head circumference. Therefore, SGA patients could effectively be characterized by early signs of systemic atherosclerosis represented by altered endothelial function.

Furthermore, the morphology of the vessels could also be impaired in SGA subjects as compared with healthy controls. We observed marked alterations in cIMT and APAO in the present SGA subjects. These results are in line with those of Stergiotou et al, who noted increased carotid and aortic IMT in SGA subjects, even after adjusting for neonatal weight and vessel diameter. ${ }^{13}$ Furthermore, low birth weight has been associated with increased cIMT in young adults who had severe fetal growth restriction and in those who had exaggerated postnatal growth. ${ }^{43}$ Martyn et al calculated a 5.3-fold increased risk of carotid stenosis and a 2.3-fold increased incidence of atherosclerotic disease in the lower limbs in patients with the lowest birth weight. ${ }^{44}$ The present data seem to confirm such a trend in SGA subjects. Such a condition is very dangerous because these data are strongly associated with cardiac disease. As outlined by Vågerö and Leon, low birth weight could increase the risk for ischemic heart disease, and such a condition may be triggered by early onset of atheroscle- 
rotic disease. ${ }^{45}$

The association between morphological and function alterations of systemic arterial vessels and the function alterations of both cardiac chambers is well-established. Bekkers et al observed that increased abdominal aorta diameter is directly related to increased ascending aorta diameter, larger LV dimensions, higher LV mass index, and lower LVEF. ${ }^{46}$ The same relationships were noted between endothelial function and myocardial performance indices. Akgul et al found that TDI determines LV performance changes in acromegaly, as well as endothelial dysfunction assessed using FMD ${ }^{47}$ Other studies noted the relationship between alteration in vascular endothelial function and myocardial performance indices. ${ }^{48,49}$ Such correlations have also been observed in pediatric patients, ${ }^{50}$ although the present study is the first to investigate all these vascular and cardiac function indices in SGA patients.

One of the most interesting research fields emerging with regard to the clinical background of SGA is related to the possible alterations of cardiac performance. The literature is undecided with regard to such matters, although the majority of studies support the present data. Most of the data relate to the neonatal period but they do not include follow-up. ${ }^{18,51,52}$ Significant variations were observed in myocardial performance indices of both RV and LV within the first month after delivery in very low-birth-weight infants. ${ }^{52}$

It is possible that the reduced anthropometric characteristics of SGA subjects may impair the development of cardiomyocytes and the intracellular molecular signaling useful for the regulation of cardiac cell proliferation, apoptosis and final differentiation..$^{53}$ Moreover, subjects with very low birth weight for gestational age have a 2.0 -fold risk increase in myocardial infarction occurrence, especially if combined with increase in body weight in adulthood (increasing the risk to 10.8 -fold). ${ }^{54}$

The present data indicate that there is reduced performance of myocardial fibers in SGA patients as compared with AGA. We found that both right and left Tei indices were higher in SGA as compared with AGA; that is, it seems that the SGA patients had reduced performance of both RV and LV in term of systolic and diastolic function. The finding that SGA patients express higher troponin I in umbilical cord blood as compared with $\mathrm{AGA}^{55}$ supports the hypothesis of original damage to cardiomyocytes, the impact of which on future cardiac performance is still unknown. Nevertheless, in the present study the subtle alteration in cardiomyocytes was reflected by TAPSE: this indirect marker of RV systolic function was reduced in SGA patients compared with controls. Although the values were all in the normal range for age and sex, the statistically significant difference could be considered a marker of future negative evolution of cardiac performance.

The most important echocardiography finding is that SGA patients had a more favorable diastolic filling pattern (elevated E/A, reduced E/e') compared with controls, but they also had impaired overall myocardial function as assessed on Tei index. The great increase in SGA E/A ratio could be considered a predisposing factor for reduced ventricle compliance rather than an amelioration of it. We considered it as a pseudonormalization pattern of the ventricle diastolic pattern. Nevertheless, E/e ratio appears to contradict such a hypothesis, although the diastolic alteration is corroborated by the increased Tei index. There may be a subtle fiber impairment in SGA patients that could alter TDI measurements, and speckle tracking may be more useful in such cases. Nevertheless, the finding of better LVEF in SGA patients compared with healthy controls is in contrast to the supposed impairment in cardiac performance in the former compared with controls. The present SGA patients had an LV function $(62.55 \pm 6.29 \%)$ higher than their counterpart $(59.62 \pm 0.10 \%, \mathrm{P}<0.001)$. Although LVEF was within the normal range (ie, higher than $55 \%$ ) in both groups, the meaning of this statistically significant difference is still a matter of debate. Further studies are needed in order to clarify the underlying mechanisms of subtle cardiac performance imbalance in SGA patients, although linked to improved LVEF.

\section{Conclusions}

SGA subjects have subtle cardiac and vascular impairment compared with healthy AGA controls. The implications of such alterations for the immediate CV future of such individuals are still unknown. Long-term follow-up is necessary in order to evaluate the effects of these alterations on morbidity and mortality.

\section{Conflict of Interest}

The authors declare no conflicts of interest.

\section{Funding Source}

None.

\section{References}

1. Clayton PE, Cianfarani S, Czernichow P, Johannsson G, Rapaport R, Rogol A. Management of the child born small for gestational age through to adulthood: A consensus statement of the International Societies of Pediatric Endocrinology and the Growth Hormone Research Society. J Clin Endocrinol Metab 2007; 92: 804-810.

2. Klammt J, Pfaffle R, Werner H, Kiess W. IGF signaling defects as causes of growth failure and IUGR. Trends Endocrinol Metab 2008; 19: $197-205$.

3. Mericq V, Ong KK, Bazaes R, Peña V, Avila A, Salazar T, et al. Longitudinal changes in insulin sensitivity and secretion from birth to age three years in small- and appropriate-for-gestational-age children. Diabetologia 2005; 48: 2609-2614.

4. Ibáñez L, Lopez-Bermejo A, Suárez L, Marcos MV, Díaz M, de Zegher F. Visceral adiposity without overweight in children born small for gestational age. J Clin Endocrinol Metab 2008; 93: 20792083.

5. Ibáñez L, Ong K, Dunger D, de Zegher F. Early development of adiposity and insulin resistance after catch-up weight gain in smallfor-gestational-age children. J Clin Endocrinol Metab 2006; 91: $2153-2158$.

6. Faienza MF, Brunetti G, Ventura A, D'Aniello M, Pepe T, Giordano $\mathrm{P}$, et al. Nonalcoholic fatty liver disease in prepubertal children born small for gestational age: Influence of rapid weight catch-up growth. Horm Res Paediatr 2013; 79: $103-109$.

7. Faienza MF, Brunetti G, Monteduro M, Cavallo L. Best determinants of nonalcoholic fatty liver disease and intra-abdominal fat in prepubertal children born small for gestational age: Ultrasound technique versus anthropometric data. Horm Res Paediatr 2013; 80: 135-136.

8. Barker DJ, Osmond C, Kajantie E, Eriksson JG. Growth and chronic disease: Findings in the Helsinki Birth Cohort. Ann Hum Biol 2009; 36: $445-458$.

9. Kerkhof GF, Leunissen RW, Hokken-Koelega AC. Early origins of the metabolic syndrome: Role of small size at birth, early postnatal weight gain, and adult IGF-I. J Clin Endocrinol Metab 2012; 97: $2637-2643$.

10. Kerkhof GF, Willemsen RH, Leunissen RW, Breukhoven PE, Hokken-Koelega AC. Health profile of young adults born preterm: Negative effects of rapid weight gain in early life. J Clin Endocrinol Metab 2012; 97: 4498-4506.

11. Leunissen RW, Kerkhof GF, Stijnen T, Hokken-Koelega AC. Effect of birth size and catch-up growth on adult blood pressure and carotid intima-media thickness. Horm Res Paediatr 2012; 77: 394-401.

12. Sebastiani G, Díaz M, Bassols J, Aragonés G, López-Bermejo A, de Zegher $\mathrm{F}$, et al. The sequence of prenatal growth restraint and postnatal catch-up growth leads to a thicker intima-media and more pre-peritoneal and hepatic fat by age 3-6 years. Pediatr Obes 2015 July 1, doi:10.1111/ijpo.12053.

13. Stergiotou I, Crispi F, Valenzuela-Alcaraz B, Cruz-Lemini M, Bijnens B, Gratacos E. Aortic and carotid intima-media thickness in term small-for-gestational-age newborns and relationship with pre- 
natal signs of severity. Ultrasound Obstet Gynecol 2014; 43: $625-$ 631.

14. Leeson CP, Kattenhorn M, Morley R, Lucas A, Deanfield JE. Impact of low birth weight and cardiovascular risk factors on endothelial function in early adult life. Circulation 2001; 103: 1264-1268.

15. Sehgal A, Doctor T, Menahem S. Cardiac function and arterial indices in infants born small for gestational age: Analysis by speckle tracking. Acta Paediatr 2014; 103: e49-e54, doi:10.1111/apa.12465.

16. Gürses D, Seyhan B. Evaluation of cardiac systolic and diastolic functions in small for gestational age babies during the first months of life: A prospective follow-up study. Cardiol Young 2013; 23: 597-605.

17. Chawengsettakul S, Russameecharoen K, Wanitpongpan P. Fetal cardiac function measured by myocardial performance index of small-for-gestational age fetuses. J Obstet Gynaecol Res 2015; 41: $222-228$.

18. Miyamoto K, Tsuboi T, Kokubu A, Suzumura H, Arisaka O. Assessment of contractility and myocardial function in small and appropriate for gestational age premature neonates using the stress-velocity relationship and tissue Doppler imaging immediately after birth. $J$ Pediatr Endocrinol Metab 2013; 26: 999-1003.

19. Czernik C, Rhode S, Metze B, Bührer C, Schmitz L. Comparison of left ventricular cardiac dimensions between small and appropriate for gestational age preterm infants below 30 weeks of gestation. J Perinat Med 2013; 41: 219-226.

20. Bertino E, Spada E, Occhi L, Coscia A, Giuliani F, Gagliardi L, et al. Neonatal anthropometric charts: The Italian neonatal study compared with other European studies. J Pediatr Gastroenterol Nutr 2010; 51: 353-361.

21. Wit JM, Boersma B. Catch-up growth: Definition, mechanisms, and models. J Pediatr Endocrinol Metab 2002; 15: 1229-1241.

22. Cacciari E, Milani S, Balsamo A, Spada E, Bona G, Cavallo L, et al. Italian cross-sectional growth charts for height, weight and BMI (2 to 20 yr). J Endocrinol Invest 2006; 29: 581-593.

23. Tanner JM, Whitehouse RH. Clinical longitudinal standards for height, weight, height velocity, weight velocity, and stages of puberty. Arch Dis Child 1976; 51: 170-179.

24. Yip PM, Chan MK, Nelken J, Lepage N, Brotea G, Adeli K. Pediatric reference intervals for lipids and apolipoproteins on the VITROS 5,1 FS Chemistry System. Clin Biochem 2006; 39: 978-983.

25. Cutfield WS, Jefferies CA, Jackson WE, Robinson EM, Hofman PL. Evaluation of HOMA and QUICKI as measures of insulin sensitivity in prepubertal children. Pediatr Diabetes 2003; 4: 119-125.

26. Pignoli P, Tremoli E, Poli A, Oreste P, Paoletti R. Intimal plus medial thickness of the arterial wall: A direct measurement with ultrasound imaging. Circulation 1986; 74: 1399-1406.

27. Touboul PJ, Hennerici MG, Meairs S, Adams H, Amarenco P, Bornstein N, et al. Mannheim carotid intima-media thickness and plaque consensus (2004-2006-2011): An update on behalf of the advisory board of the 3rd, 4th and 5th watching the risk symposia, at the 13th, 15th and 20th European Stroke Conferences, Mannheim, Germany, 2004, Brussels, Belgium, 2006, and Hamburg, Germany, 2011. Cerebrovasc Dis 2012; 34: 290-296.

28. Ciccone MM, Bilianou E, Balbarini A, Gesualdo M, Ghiadoni L, Metra M, et al. Task force on: 'Early markers of atherosclerosis: Influence of age and sex'. J Cardiovasc Med (Hagerstown) 2013; 14: $757-766$.

29. Fleiss JL. The design and analysis of clinical experiments. New York: Wiley, 1986

30. Miniello VL, Faienza MF, Scicchitano P, Cortese F, Gesualdo M, Zito A, et al. Insulin resistance and endothelial function in children and adolescents. Int J Cardiol 2014; 15: 343-347.

31. Corretti MC, Anderson TJ, Benjamin EJ, Celermajer D, Charbonneau F, Creager MA, et al. Guidelines for the ultrasound assessment of endothelial-dependent flow-mediated vasodilation of the brachial artery: A report of the International Brachial Artery Reactivity Task Force. J Am Coll Cardiol 2002; 39: 257-265.

32. Lopez L, Colan SD, Frommelt PC, Ensing GJ, Kendall K, Younoszai $\mathrm{AK}$, et al. Recommendations for quantification methods during the performance of a pediatric echocardiogram: A report from the Pediatric Measurements Writing Group of the American Society of Echocardiography Pediatric and Congenital Heart Disease Council. J Am Soc Echocardiogr 2010; 23: 465-495.

33. Tei C. New non-invasive index for combined systolic and diastolic ventricular function. J Cardiol 1995; 26: 396-404.

34. Arques S, Roux E, Luccioni R. Current clinical applications of spectral tissue Doppler echocardiography (E/Ew ratio) as a noninvasive surrogate for left ventricular diastolic pressures in the diagnosis of heart failure with preserved left ventricular systolic function. Cardiovascular Ultrasound 2007; 26: 5-16.
35. Ciccone MM, Scicchitano P, Zito A, Gesualdo M, Sassara M, Calderoni G, et al. Different functional cardiac characteristics observed in term/preterm neonates by echocardiography and tissue Doppler imaging. Early Hum Dev 2011; 87: 555-558.

36. Hashimoto I, Watanabe K. Alternation of right ventricular contraction pattern in healthy children: Shift from radial to longitudinal direction at approximately $15 \mathrm{~mm}$ of tricuspid annular plane systolic excursion. Circ J 2014; 78: 1967-1973.

37. JCS Joint Working Group. Guidelines for drug therapy in pediatric patients with cardiovascular diseases (JCS 2012): Digest version. Circ J 2014; 78: 507-533.

38. Visentin S, Grumolato F, Nardelli GB, Di Camillo B, Grisan E, Cosmi E. Early origins of adult disease: Low birth weight and vascular remodeling. Atherosclerosis 2014; 237: 391-399.

39. Jouret B, Dulac Y, Bassil Eter R, Taktak A, Cristini C, Lounis N, et al. Endothelial function and mechanical arterial properties in children born small for gestational age: Comparison with obese children. Horm Res Paediatr 2011; 76: 240-247.

40. de Arriba A, Domínguez M, Labarta JI, Domínguez M, Puga B, Mayayo E, et al. Metabolic syndrome and endothelial dysfunction in a population born small for gestational age relationship to growth and Gh therapy. Pediatr Endocrinol Rev 2013; 10: 297-307.

41. Ligi I, Simoncini S, Tellier E, Grandvuillemin I, Marcelli M, Bikfalvi A, et al. Altered angiogenesis in low birth weight individuals: A role for anti-angiogenic circulating factors. J Matern Fetal Neonatal Med 2014; 27: 233-238.

42. Touwslager RN, Houben AJ, Gielen M, Zeegers MP, Stehouwer CD, Zimmermann LJ, et al. Endothelial vasodilatation in newborns is related to body size and maternal hypertension. J Hypertens 2012; 30: $124-131$.

43. Oren A, Vos LE, Uiterwaal CS, Gorissen WH, Grobbee DE, Bots ML. Birth weight and carotid intima-media thickness: New perspectives from the atherosclerosis risk in young adults (ARYA) study. Ann Epidemiol 2004; 14: 8-16.

44. Martyn CN, Gale CR, Jespersen S, Sherriff SB. Impaired fetal growth and atherosclerosis of carotid and peripheral arteries. Lancet 1998; 352: 173-178.

45. Vågerö D, Leon D. Ischaemic heart disease and low birth weight: A test of the fetal-origins hypothesis from the Swedish Twin Registry. Lancet 1994; 343: 260-263.

46. Bekkers SC, Habets JH, Cheriex EC, Palmans A, Pinto Y, Hofstra $\mathrm{L}$, et al. Abdominal aortic aneurysm screening during transthoracic echocardiography in an unselected population. J Am Soc Echocardiogr 2005; 18: 389-393.

47. Akgul E, Tokgozoglu SL, Erbas T, Kabakci G, Aytemir K, Haznedaroglu I, et al. Evaluation of the impact of treatment on endothelial function and cardiac performance in acromegaly. Echocardiography 2010; 27: 990-996.

48. Chand S, Chue CD, Edwards NC, Hodson J, Simmonds MJ, Hamilton A, et al. Endothelial nitric oxide synthase single nucleotide polymorphism and left ventricular function in early chronic kidney disease. PLoS One 2015; 10: e0116160, doi:10.1371/journal.pone. 0116160 .

49. Fernlund E, Schlegel TT, Platonov PG, Carlson J, Carlsson M, Liuba P. Peripheral microvascular function is altered in young individuals at risk for hypertrophic cardiomyopathy and correlates with myocardial diastolic function. Am J Physiol Heart Circ Physiol 2015; 308: H1351-H1358.

50. Alp H, Eklioğlu BS, Atabek ME, Karaarslan S, Baysal T, Altın H, et al. Evaluation of epicardial adipose tissue, carotid intima-media thickness and ventricular functions in obese children and adolescents. J Pediatr Endocrinol Metab 2014; 27: 827-835.

51. Helfer S, Schmitz L, Bührer C, Czernik C. Tissue Doppler-derived strain and strain rate during the first 28 days of life in very low birth weight infants. Echocardiography 2014; 31: 765-772.

52. Murase M, Ishida A, Morisawa T. Left and right ventricular myocardial performance index (Tei index) in very-low-birth-weight infants. Pediatr Cardiol 2009; 30: 928-935.

53. Botting KJ, Wang KC, Padhee M, McMillen IC, Summers-Pearce B, Rattanatray L, et al. Early origins of heart disease: Low birth weight and determinants of cardiomyocyte endowment. Clin Exp Pharmacol Physiol 2012; 39: 814-823.

54. Rajaleid K, Janszky I, Hallqvist J. Small birth size, adult overweight, and risk of acute myocardial infarction. Epidemiology 2011; 22: $138-147$.

55. Chaiworapongsa T, Espinoza J, Yoshimatsu J, Kalache K, Edwin S, Blackwell S, et al. Subclinical myocardial injury in small-for-gestational-age neonates. J Matern Fetal Neonatal Med 2002; 11: $385-$ 390. 